\title{
USO DE VEÍCULO AÉREO NÃO TRIPULADO COMO FACILITADOR PARA A REALIZAÇÃO DO CADASTRO AMBIENTAL RURAL-CAR
}

Fernando da Silva Alexandre ${ }^{(a)}$, Renilson Pinto da Silva Ramos ${ }^{(b)}$, Rodolfo Alexandre da Silva Gomes de Deus ${ }^{(\mathrm{c})}$, Daniel Dantas Moreira Gomes ${ }^{(\mathrm{d})}$

(a) Geografia/Campus Garanhuns, Universidade de Pernambuco, fnando257@ gmail.com

(b) Geografia/Campus Garanhuns, Universidade de Pernambuco, renilsonr5@ hotmail.com

(c) Geografia/Campus Garanhuns, Universidade de Pernambuco, rdolfodeus@ gmail.com

(d) Geografia/Campus Garanhuns, Universidade de Pernambuco, daniel.gomes@upe.br

Eixo: GEOTECNOLOGIAS E MODELAGEM ESPACIAL EM GEOGRAFIA FÍSICA

\section{RESUMO}

O Cadastro Ambiental Rural-CAR é um registro eletrônico obrigatório para todos os imóveis rurais, que tem por finalidade integrar as informações ambientais referentes à situação das Áreas de Preservação Permanente - APP, das áreas de Reserva Legal - RL, das florestas e dos remanescentes de vegetação nativa, das Áreas de Uso Restrito e das áreas consolidadas, e um dos meios mais viáveis para a obtenção dos dados para o CAR é o sensoriamento remoto, através da aerofotogrametria de pequeno formato, que possibilitou mapear todas as feições do terreno requisitadas pelo sistema do CAR.

Palavras chave: aerofotogrametria, sensoriamento remoto, Cadastro Ambiental Rural, Palmeirina-PE

\section{Introdução}

Preocupando-se com a necessidade da conservação dos biomas brasileiros, em vista do mau uso do solo, causando grandes danos ao meio natural, em 2012 o governo federal implementa uma nova lei ambiental (Lei 12.651/2012), denominada de Cadastro Ambiental Rural (CAR), que legitima a obrigatoriedade cadastral de toda gleba de terra pertencente ao pequeno, médio e grande proprietário rural, o CAR é uma base de dados estratégica para a gestão ambiental do país e contribui para o controle, monitoramento e combate ao desmatamento das florestas e demais representações da vegetação nativa do Brasil, bem como para o planejamento ambiental e econômico dos imóveis rurais.

O CAR é um registro eletrônico obrigatório para todos os imóveis rurais, que tem por finalidade integrar as informações ambientais referentes à situação das Áreas de Preservação Permanente APP, das áreas de Reserva Legal - RL, das florestas e dos remanescentes de vegetação nativa, das Áreas de Uso Restrito e das áreas consolidadas das propriedades e posses rurais do país, sendo obrigatório que o proprietário se cadastre e cadastre seu imóvel no sistema do Sicar até 31/12/2017, 
havendo consequências para quem não fizer o $\mathrm{CAR}$, como multas ambientais e fim do crédito agrícola (SERVIÇO FLORESTAL BRASILEIRO, 2016).

E um dos melhores meios de se fazer o levantamento de uma grande área é o Sensoriamento Remoto juntamente com o Geoprocessamento (ROSA, 2009), e para cumprir os requisitos de qualidade requeridas no cadastro e visando obter alta produtividade com baixo custo na aquisição das cenas, entra em cena a aerofotogrametria com os Veículos Aéreos não Tripulados (VANTs), que são pequenas aeronaves equipadas com sensores óticos capazes de gerar ortomosaicos e modelos de elevação de forma automática ou não, em conjunto com um Sistema de Informações Geográficas (SIG), que permitirá organizar, gerir e classificar os dados obtidos após o levantamento em campo (GOMES et al., 2014). Este trabalho tem como principal objetivo analisar a facilidade proporcionada pela aerofotogrametria juntamente com o Geoprocessamento para a realização do Cadastro Ambiental Rural-CAR, em um imóvel na cidade de Palmeirina-PE, figura 1.

\section{Materiais e métodos}

\subsection{Materiais}

Inicialmente fez-se o levantamento do material bibliográfico e cartográfico base. Foram consultados, livros, artigos, teses, monografias, dissertações e trabalhos técnicos, para dar fomento teórico a pesquisa.

Para a realização deste trabalhou se utilizou o VANT da fabricante chinesa DJI, Phantom 3 Advanced, equipado com uma câmera Phantom Vision de 12 Megapixels, com o sistema GPS e Glonass, com tempo de voo de aproximadamente 23 minutos por bateria, sua escolha deu-se por ser um veículo automático de baixo custo. O mesmo propiciou a obtenção de 352 cenas em 1 voo com altitude média de 80 metros em relação ao solo, seguindo a orientação Legal vigente, que implica um voo a uma altura máxima de 120 metros a cima do nível do solo (SILVA et al., 2015).

Os dados cartográficos foram armazenados no $\operatorname{ArcGIS}^{\circledR} 10.3$ possibilitando o armazenamento e o gerenciamento dos dados em um banco de dados criado no próprio software, facilitando se trabalhar as cenas e outros dados.

A metodologia adotada foi dividida em 4 partes principais, que abrangem desde o planejamento de voo até a obtenção dos dados cadastrais para a realização do CAR, em síntese na figura 2, e mais detalhado nos tópicos abaixo. 


\subsection{Planejamento de voo}

Inicialmente antes do planejamento de voo se tinha a necessidade da escolha do objeto de estudo, sendo escolhido um imóvel rural no Sítio Caldeirão pertencente ao sr. José Alexandre Filho, no município de Palmeirina-PE, sua escolha se deu por este ser um imóvel com uma área pequena, cerca de 4,91 hectares, mas com grande diversidade de usos e culturas.

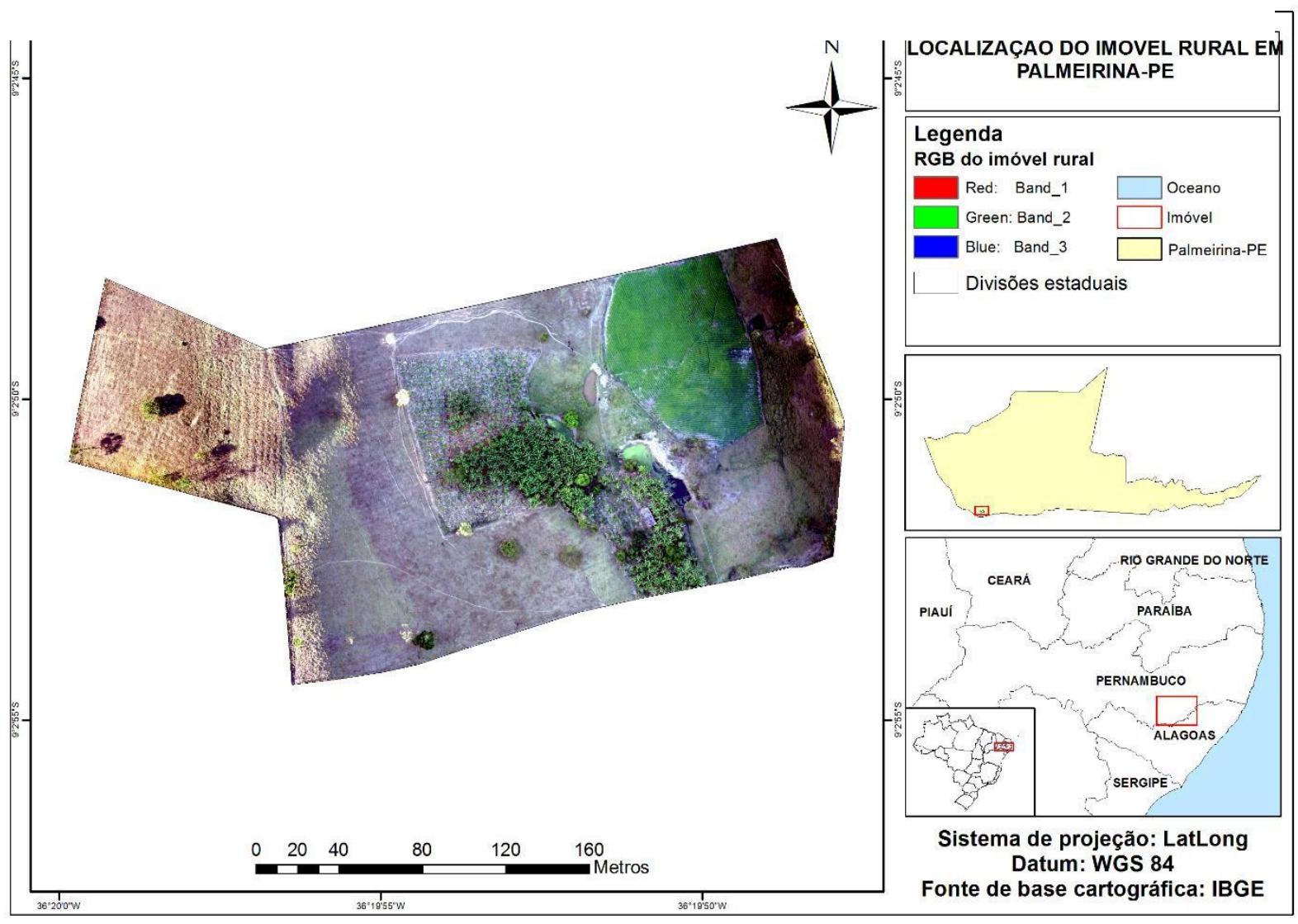

Logo após a escolha do objeto de estudo, foi feito o planejamento para o voo, considerando as condições meteorológicas (vento e chuva) do dia escolhido para a realização do voo, com as condições adequadas fazia-se o plano de voo, visando melhores resultados foi decidido que o voos teria um recobrimento longitudinal de $80 \%$ e lateral de 60\% para melhores resultados, já que segundo Fitz (2008), tem-se que haver no mínimo uma sobreposição longitudinal de $60 \%$ e lateral de $30 \%$, logo em seguida foram escolhidos 13 pontos estratégicos distribuídos pelo terreno para a sinalização dos pontos de controle, que foram georreferenciados com um GPS de navegação Etrex Vista $H$.

\subsection{Execução do voo}


XVII Simpósio Brasileiro

de Geografia Física Aplicada

I Congresso Nacional

de Geografia Física
OS DESAFIOS DA GEOGRAFIA FÍSICA NA FRONTEIRA DO CONHECIMENTO

Instituto de Geociências - Unicamp

Campinas - SP

28 de Junho à 02 de Julho de 2017

Este ponto teve início com a verificação dos equipamentos antes do voo, para que durante a execução do plano de voo o VANT e os equipamentos não sofressem algum dano, caso houvesse algum problema técnico com a aeronave ou equipamentos de solo a missão seria abortada.

Pelo Phantom 3 Advanced ser um multimotor, o mesmo decola de forma vertical, facilitando assim o processo. A partir da decolagem em modo manual até a altitude de 50 metros, há o acionamento do piloto automático, que irá elevar a aeronave até 80 metros e iniciar o plano de voo e a tomada das cenas, o voo teve uma duração de 16 minutos por motivos de segurança, já que a bateria dura em média 23 minutos de voo. Logo após concluído o voo, o VANT retorna até o ponto de decolagem, por meio do Go To Home, pousando de modo vertical, em um raio de 3 metros do ponto de decolagem.

\subsection{Pós voo}

Finalizado o voo, ocorre a avaliação das fotografias obtidas e da rota do GPS, avaliando o contraste e a nitidez das fotografias, enquanto que na rota se verifica se o VANT não se distanciou demais da rota planejada devido ao vento ou algum problema com o GPS. Após a verificação dos dados, as cenas foram armazenadas em um Geodatabase no ArcGIS 10.3.

Após os dados armazenados em um Banco de Dados (BD), utilizou-se o software Argisoft PhotoScan Professional, para gerar o ortomosaico e a correção por meio dos pontos de controle, levando cerca de 56 horas de processamento, obtendo um ortomosaico com $2,7 \mathrm{~cm} /$ pix de resolução espacial.

As cinco etapas básicas do processamento com o Photoscan são: (1) calibração automática da câmera com base nos dados do EXIF das fotografias; (2) alinhamento das fotos - a partir dos pontos em comum entre as fotografias; (3) geração da nuvem de pontos - com base nas posições estimadas das fotografias são identificadas as coordenadas $\mathrm{x}$, y e z; (4) criação de um MDS de malha triangular - usando a nuvem de pontos como nós, é gerada uma estrutura do tipo vetorial com topologia do tipo nó-arco que representa a superfície através de um conjunto de faces triangulares interligadas; (5) geração do ortomosaico - gerado a partir da texturização da geometria construída pela malha triangular.

\subsection{Cadastro Ambiental Rural}

Em posse do ortomosaico foi possível identificar as várias feições do terreno e delimitar cada área e a inserção dos dados para a realização do CAR, inicialmente foi feito a delimitação das feições do terreno para a etapa "Geo", após a geração do ortomosaico, o mesmo foi exportado para o ArcGIS 10.3, logo em seguida se criou shapefiles para delimitar os usos e as benfeitorias do imóvel. 


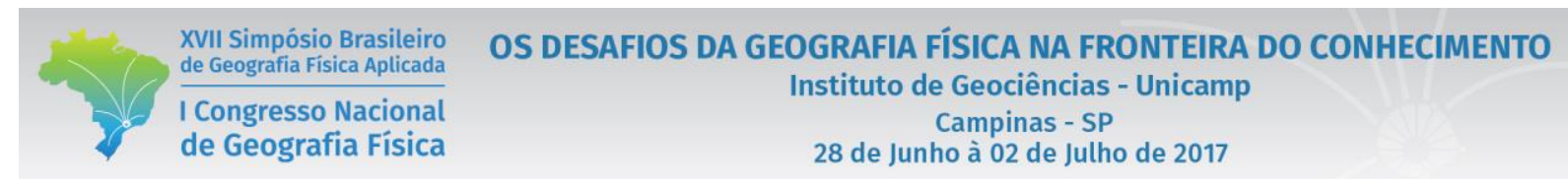

As seis etapas para a realização do CAR no sistema são: (1) Cadastrante - O programa irá pedir os dados do cadastraste do imóvel sendo ele representante ou não do proprietário; (2) Imóvel - nesta etapa é pedida todas as informações referentes aos dados do imóvel e endereço de correspondência do proprietário; (3) Domínio - Nesta etapa o usuário deverá cadastrar o(s) proprietário(s)/possuidor(es) do imóvel em questão;

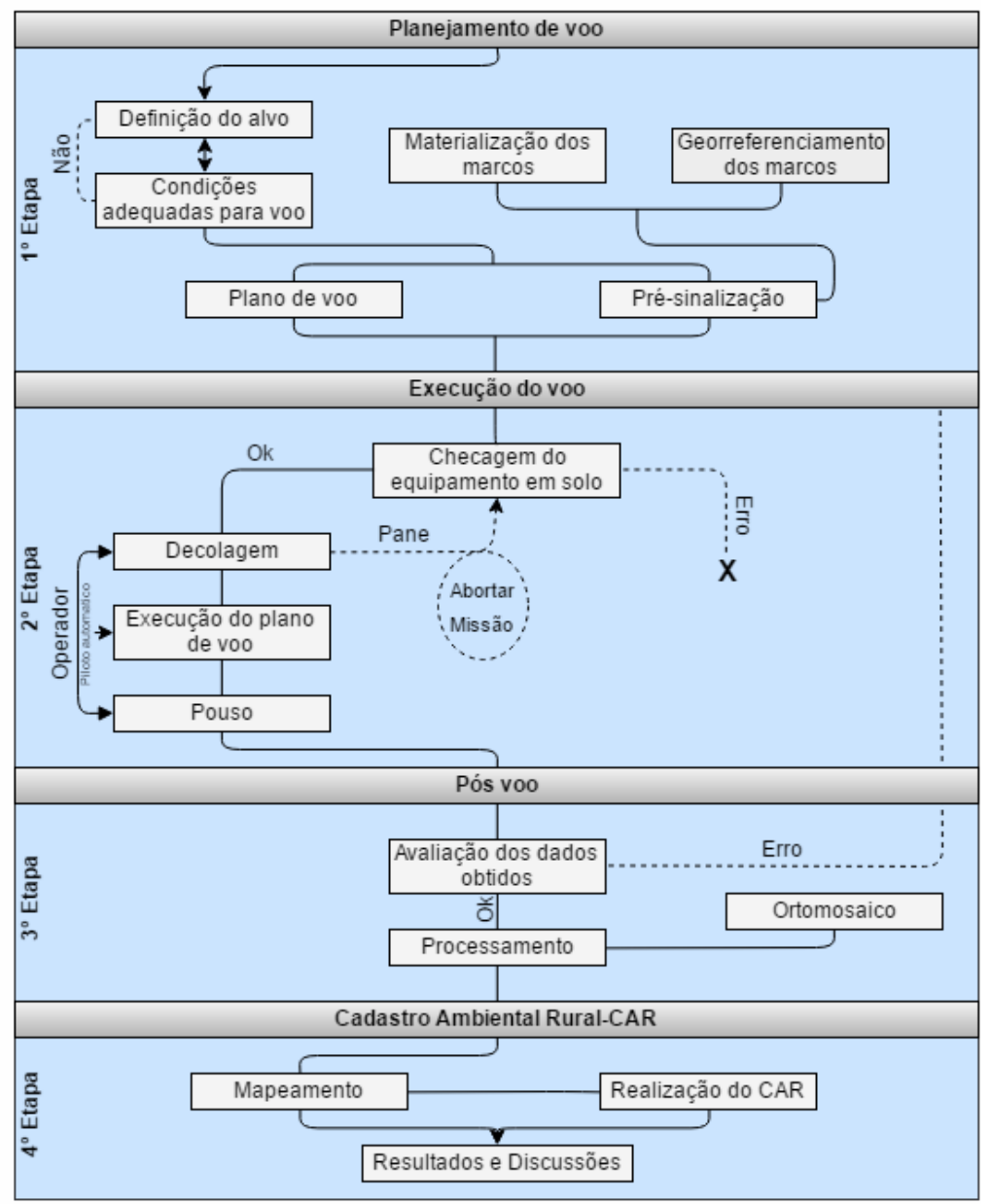

Figura 2. Fluxograma com as etapas metodológicas.

(4) Documentação - o cadastrante irá informar toda a documentação do imóvel, sendo propriedade ou posse, casa não exista nenhum documento, poderá ser feito um termo de auto declaração; (5) Geo aqui o cadastrante irá informar todas as feições do terreno (Área d imóvel, cobertura do solo, servidão administrativa, APP/uso restrito e reserva legal) através de dados vetoriais, melhor explicados no tópico 
abaixo; Informações - esta etapa apresenta um questionário ao usuário para que sejam fornecidas algumas informações específicas sobre o imóvel.

\subsection{Etapa Geo}

Nos tópicos abaixo há a descrição detalhada de cada uma das seis etapas na ferramenta Geo segundo o Serviço Florestal Brasileiro (2016).

- Área do Imóvel: Este passo é obrigatório no cadastro ambiental rural. Corresponde à área total do imóvel que está sendo cadastrado. É considerada como sendo o conjunto de propriedades ou posses distribuídas de forma contínua, pertencentes a um ou mais proprietários ou possuidores rurais. Eventualmente a área declarada constante nos documentos podem não corresponder com o desenho elaborado, já que algumas áreas foram obtidas com instrumentos sem precisão, o que não impede a conclusão do registro no CAR. No entanto, deve ser evitado o desenho sobre áreas de outros imóveis rurais, evitando sobreposições, já que as declarações no CAR não geram benefício fundiário e no processo de análise o registro poderá ser suspenso. Neste passo, ainda é obrigatório a indicação da "Sede ou Ponto de Referência do Imóvel";

- Cobertura do Solo: São áreas no interior do imóvel rural, que são constituídas por “Área de Pousio, “Área Consolidada" e "Remanescente de Vegetação Nativa”;

- Servidão Administrativa: Corresponde às áreas ocupadas por estradas, outras obras públicas que recortam o interior do imóvel rural. A descrição destas áreas é fundamental para que se obtenha o cálculo da área líquida do imóvel rural, o que dará condições de projetar a área necessária a ser mantida como dispositivo da Reserva Legal. O georreferenciamento pode ser classificado como "Infraestrutura Pública", "Utilidade Pública" ou "Reservatório para Abastecimento ou Geração de Energia";

- APP/Uso Restrito: As APP's são áreas definidas no Código Florestal como sendo aquelas destinadas à proteção da diversidade biológica associadas aos mananciais hídricos, ao relevo e às áreas especiais de grande relevância ambiental. As APP's são definidas por parâmetros dimensionais que devem ser respeitados no desenho individual de cada APP's existente no interior do imóvel. O georreferenciamento pode ser classificado como Uso restrito ou Área de Preservação Permanente;

- Reserva Legal: São áreas no interior do imóvel rural que serão instituídas voluntariamente, temporária ou perpetuamente, para conservação dos recursos naturais. O georreferenciamento neste passo pode ser classificado como "Reserva Legal Proposta", "Reserva Legal Averbada", "Reserva 
XVII Simpósio Brasileiro

de Geografia Física Aplicada

I Congresso Nacional

de Geografia Física
OS DESAFIOS DA GEOGRAFIA FÍSICA NA FRONTEIRA DO CONHECIMENTO

Instituto de Geociências - Unicamp

Campinas - SP

28 de Junho à 02 de Julho de 2017

Legal Aprovada e não Averbada" e "Reserva Legal vinculada à compensação de outro imóvel".

\section{Resultados e discussões}

Embora o VANT Phantom 3 Advanced seja de pequeno porte, o mesmo desempenhou a função de obter cenas para a geração do ortomosaico. Porém não se recomenda o mesmo para áreas superiores a 30 hectares, devido ao pouco tempo de voo propiciado pela bateria e as limitações do mesmo.

Com a utilização dos pontos de controle foi possível diminuir o erro médio de deslocamento de 4,42 metros para 2,21 metros, mostrando assim a indispensável necessidade de se obter pontos de controle no caso da aerofotogrametria para a realização do CAR, com a correção do erro de descolamento foi possível mapear todas as feições do imóvel, percebe-se na tabela 1 a área de cada classe bidimensional, os dados unidimensionais foram as nascentes e a sede do imóvel, ao todo foram cadastradas 5 nascentes perenes.

Tabela 1. Área de cada classe na etapa Geo.

\begin{tabular}{|c|c|c|}
\hline \multirow{2}{*}{$\begin{array}{c}\text { Geo } \\
\text { Área do Imóvel }\end{array}$} & Classe & Área (Hectares) \\
\cline { 2 - 3 } & Imóvel & 4,9150 \\
Cobertura do Solo & Area consolidada & 4,8668 \\
\cline { 2 - 3 } Servidão & Vegetação nativa & 0 \\
\hline Administrativa & Area de pousio & 0,5254 \\
\hline APP/Uso Restrito & Nenhuma detectada no imóvel & 0 \\
\hline & APP & 2,3805 \\
Reserva Legal & Declividades de 25 a 45 graus & 1,7192 \\
& Reservatório artificial & 0,0482 \\
\hline & Reserva legal proposta & 1,2502 \\
\hline
\end{tabular}

$\mathrm{O}$

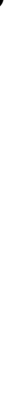

VANT Phantom 3 se mostrou uma ótima ferramenta para levantar cenas de pequenas áreas, o mesmo propiciou uma grande economia de tempo em campo, já em contrapartida houve um acréscimo de tempo em escritório se comparado aos métodos que utilizam os sistemas de localização do satélite. A metodologia adotada permitiu desde o planejamento de voo, levantamento em campo e o processamento das cenas em Software especifico até a realização do Cadastro Ambiental Rural e posterior envio para o sistema do Sicar. Pode-se perceber na figura 3 o mapa temático final do imóvel rural, com todas as feições vetorizadas e georreferenciadas. 
O VANT Phantom 3 se mostrou uma ótima ferramenta para levantar cenas de pequenas áreas, o mesmo propiciou uma grande economia de tempo em campo, já em contrapartida houve um acréscimo de tempo em escritório se comparado aos métodos que utilizam os sistemas de localização do satélite. A metodologia adotada permitiu desde o planejamento de voo, levantamento em campo e o processamento das cenas em Software especifico até a realização do Cadastro Ambiental Rural e posterior envio para o sistema do Sicar. Pode-se perceber na figura 3 o mapa temático final do imóvel rural, com todas as feições vetorizadas e georreferenciadas.

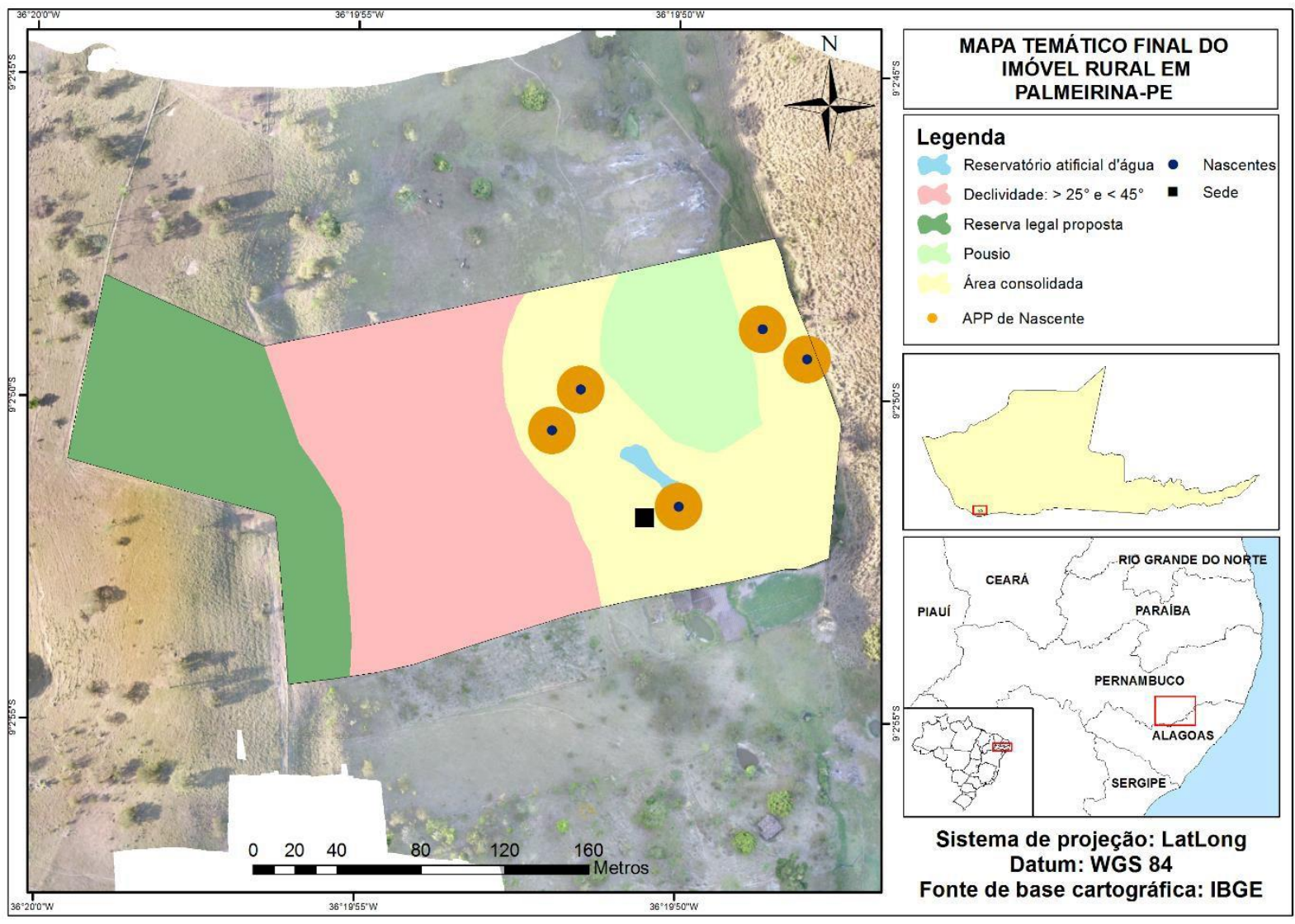

Figura 3. Mapa temático final.

\section{Conclusões}

A aerofotogrametria propiciou o levantamento e o mapeamento de todos os dados do imóvel rural, com grande qualidade cartográfica, mostrando que atualmente os VANTs são uma das formas mais cômodas e com melhores resultados para a realização do Cadastro Ambiental Rural-CAR. 
Percebeu-se que a junção dessa ferramenta com o Geoprocessamento é uma poderosa aliada na gestão territorial e levantamento cadastral, ficando agora a validação do CAR para o órgão responsável no estado.

5. Referências bibliográficas

DUARTE. P.A. Fundamentos de Cartografia. 3. Ed. Florianópolis. UFSC, 2008.

FITZ, P. R. Geoprocessamento sem complicação. 3.ed. revisada e ampliada. São Paulo. 2013. 26p.

SERVIÇO FLORESTAL BRASILEIRO: Manual Cadastro Ambiental Rural-CAR. Ministério Do Meio Ambiente, Brasília, 2016.

SILVA, C. A.; DUARTE. C. R.; SOUTO. M. V. S.; SABADIA. J. A. B.: Utilização de VANT

para geração de ortomosaicos e aplicação do Padrão de Exatidão Cartográfica (PEC). Anais XVII Simpósio Brasileiro de Sensoriamento Remoto - SBSR, João Pessoa-PB, Brasil, 25 a 29 de abril de 2015, INPE.

SOUZA. G.C.: Análise de metodologias no levantamento de dados espaciais para cadastro urbano. Dissertação de mestrado. Universidade de São Paulo. São Carlos. 2001

ROSA. R. Introdução ao sensoriamento remoto. 7 ed. São Paulo

6. Agradecimentos

Os autores agradecem a Universidade de Pernambuco (UPE) pelo financiamento dos recursos do projeto de pesquisa "Análise De Riscos Socioambientais em Bacias Hidrográficas Através da Utilização de Ferramentas de Geoprocessamento e Aerofotogrametria De Pequeno Formato", junto ao Programa de Fortalecimento Acadêmico (PFA/IC), ao Laboratório de Geoprocessamento e Modelagem Ambiental pelo apoio em todo o decorrer da pesquisa e ao Sr, José Alexandre Filho por te cedido os dados de seu imóvel. 